\title{
Acute exacerbation of upper airway obstruction in acromegaly
}

\author{
P. J. REES \\ M.R.C.P. \\ J. G. HAY \\ M.R.C.P. \\ J. R. WEBB \\ M.R.C.P. \\ Respiratory Function Laboratory, Brook Hospital, Shooters Hill, London SE18
}

\begin{abstract}
Summary
A 71-year-old man with acromegaly is described. Investigations for dyspnoea and daytime somnolence showed upper airway obstruction but not sleep apnoea. An upper respiratory tract infection precipitated stridor which required urgent tracheostomy.

\section{Introduction}

Obstruction of the upper airway is recognized as a feature of acromegaly. Evans, Hipkin and Murray (1977) found abnormal flow volume curves suggesting upper airway obstruction in 6 out of 20 patients with acromegaly and no other cardiorespiratory disease. Such obstruction has been proposed as a cause of shortness of breath (Siegler, 1952), problems with endotracheal intubation (Kitahata, 1971), and obstructive sleep apnoea (Perks et al., 1980). On occasions it has necessitated tracheostomy (Jackson, 1918; Grotting \& Pemberton, 1950). Jackson recommended routine examination of the larynx in acromegaly but upper airway obstruction still goes unrecognized. We report a case where sudden exacerbation of the obstruction by an upper respiratory tract infection precipitated stridor requiring urgent tracheostomy.
\end{abstract}

\section{Case report}

A 71-year-old man was seen because of increasing shortness of breath. He had been diagnosed as having acromegaly 4 years previously but the condition was thought to be static and no treatment had been given. His family complained of his loud nocturnal snoring and he had noticed daytime somnolence.

Investigations showed mild expiratory airflow obstruction and marked inspiratory airflow obstruction with a maximal mid-inspiratory flow of 40 litre/min (Fig. 1). Mixed venous $\mathrm{PCO}_{2}$ was raised at $9 \cdot 7 \mathrm{kPa}$ (normal 5.6-7.0). A sleep study showed no evidence of pathological sleep apnoea.

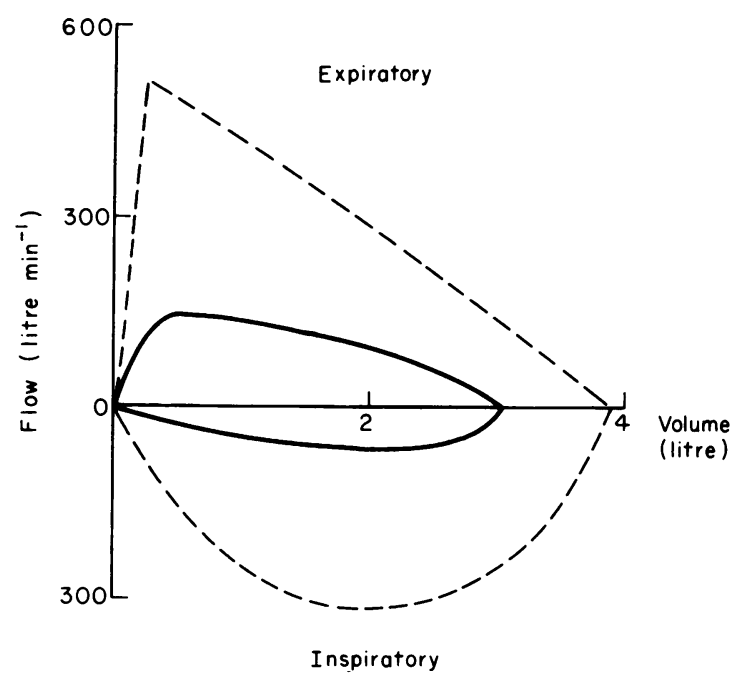

FIG. 1. The broken line shows the predicted maximal flow volume curve for the patient described. The unbroken line shows the actual curve obtained. The severe limitation of flow during expiration and, to a greater degree, during inspiration is typical of severe, extrathoracic, upper airway obstruction.

While undergoing investigation he developed an upper respiratory tract infection and over $24 \mathrm{hr}$ became acutely short of breath with inspiratory stridor. Indirect laryngoscopy was not possible because of enlargement of the tongue and a tracheostomy was performed the same day. The trachea was hard and difficult to incise. Postoperatively he felt considerably less breathless. Six weeks later his mixed venous $\mathrm{PCO}_{2}$ had fallen to $7 \cdot 6 \mathrm{kPa}$ and his maximal mid-inspiratory flow with the tracheostomy tube in place but obstructed was $60 \mathrm{litre} / \mathrm{min}$. Fibreoptic laryngoscopy showed thickening of true and false cords with very restricted opening of the vocal cords on inspiration. Biopsy of the cords at the 
time of tracheostomy showed oedema and chronic inflammation. Growth hormone levels were raised during a glucose tolerance test and he subsequently underwent external radiotherapy treatment to the pituitary.

\section{Discussion}

Extrathoracic airway obstruction should always be considered in patients with unusual features of airflow obstruction. This can be demonstrated by looking at the inspiratory limb of an inspiratoryexpiratory flow volume loop. The maximal inspiratory flow at $50 \%$ vital capacity was very low in this patient while expiratory obstruction which had been assumed to be the cause of his dyspnoea was only mild. In the patient described the addition of an upper respiratory tract infection produced acute, lifethreatening upper airway obstruction for which urgent tracheostomy was necessary. This case also demonstrates the technical problems with examination of the larynx and with tracheostomy in such patients.

Laryngeal obstruction in acromegaly has previously been ascribed to interference with the cricoarytenoid joint, or to stretching of the recurrent laryngeal nerves as the larynx enlarges upwards (Siegler, 1952). However, diminished movements of the vocal cords are probably related to thickening of laryngeal structures demonstrated in this case at laryngoscopy and on vocal cord biopsy. Grotting and Pemberton (1950) described seven cases of acrome- galy with fixation of the vocal cords. Three of thesễ patients underwent tracheostomy; two were shortl after operations on their thyroid glands while one patient also developed stridor precipitated by $\mathfrak{a}$. respiratory infection.

Laryngeal obstruction should be considered acromegalic patients complaining of breathlessness? and investigation should include inspiratory an expiratory maximum flow volume curves (Evans $e \frac{F}{\sigma}$ al., 1977). Breathlessness, carbon dioxide retention and daytime somnolence are not necessarily associen ated with sleep apnoea. Additional problems such as respiratory infections or attempts at endotracheat intubation (Kitahata, 1971) may precipitate the need for urgent tracheostomy in such patients.

\section{Acknowledgments}

We should like to thank Dr C. McKerron and Mr A. E. Howart for permission to report this case.

\section{References}

Evans, C.C., Hipkin, L.J. \& MUrRay, G.M. (1977) Pulmonar? function in acromegaly. Thorax, 32, 322.

Grotting, J.K. \& PEMBerton, J. DE J. (1950) Fixation of the vocad cords in acromegaly. Archives of Otolaryngology, 12, 608.

JACKSON, C. (1918) Acromegaly of the larynx. Journal of the American Medical Association, 71, 1787.

KiTAHATA, L.M. (1971) Airway difficulties associated with anaesthe sia in acromegaly. British Journal of Anaesthesia, 43, 1187.

PERKS, W.H., HORROCKS, P.M., COOPER, R.A., BRADBURY Allen, A., Baldock, N., Prowse, K. \& VAN'T HofF, W. (180 Sleep apnoea in acromegaly. British Medical Journal, 280, 894.

SIEGLER, J. (1952) Acromegaly associated with laryngeal obstructio Journal of Laryngology and Otology, 66, 620. 